J. Dairy Sci. 95:6397-6408

http://dx.doi.org/10.3168/jds.2011-5173

(C) American Dairy Science Association ${ }^{\circledR}$, 2012. Open access under CC BY-NC-ND license.

\title{
Bioinformatics analysis of microRNA and putative target genes in bovine mammary tissue infected with Streptococcus uberis ${ }^{1}$
}

\author{
A. Naeem, ${ }^{*} \dagger^{2}$ K. Zhong,‡ S. J. Moisá, ${ }^{\dagger} \dagger$ J. K. Drackley, $† \S$ K. M. Moyes,\# and J. J. Loor ${ }^{\star} \S^{3}$ \\ *Mammalian NutriPhysioGenomics, and \\ †Department of Animal Sciences, University of Illinois, Urbana 61801 \\ $\ddagger$ Technological College of Animal Husbandry and Veterinary Medicine, Henan Agricultural University, Zhengzhou, 450002, China \\ §Division of Nutritional Sciences, University of Illinois, Urbana 61801 \\ \#Department of Animal and Avian Sciences, University of Maryland, College Park 20742
}

\section{ABSTRACT}

MicroRNA (miRNA) are small single-stranded noncoding RNA with important roles in regulating innate immunity in nonruminants via transcriptional and posttranscriptional mechanisms. Mastitis causes significant losses in the dairy industry and a wealth of large-scale mRNA expression data from mammary tissue have provided fundamental insights into the tissue adaptations to pathogens. We studied the expression of 14 miRNA (miR-10a, -15b, -16a, -17, -21, -31, -145, -146a, -146b, -155, -181a, -205, -221, and -223) associated with regulation of innate immunity and mammary epithelial cell function in tissue challenged with Streptococcus uberis. Those data, along with microarray expression of 2,102 differentially expressed genes, were used for bioinformatics analysis to uncover putative target genes and the most affected biological pathways and functions. Three miRNA (181a, 16, and 31) were downregulated approximately 3 - to 5 -fold and miR-223 was upregulated approximately 2.5 -fold in infected versus healthy tissue. Among differentially expressed genes due to infection, bioinformatics analysis revealed that the studied miRNA share in the regulation of a large number of metabolic (SCD, CD36, GPAM, and FASN), immune/oxidative stress (TNF, IL6,IL10, SOD2, LYZ, and TLR4), and cellular proliferation/differentiation (FOS and CASP4) target genes. This level of complex regulation was underscored by the coordinate effect revealed by bioinformatics on various cellular pathways within the Kyoto Encyclopedia of Genes and Genomes database. Most pathways associated with "cellular pro-

Received November 22, 2011.

Accepted July 25, 2012.

${ }^{1}$ Supported by funds from Section 1433 Animal Health and Disease Funds appropriated to the Illinois Agricultural Experiment Station (Urbana, IL) under project no. ILLU-538-981 and ILLU-538-923.

${ }^{2}$ Present address: Department of Biosciences, COMSATS Institute of Information Technology, Park Road, Islamabad 45600, Pakistan.

${ }^{3}$ Corresponding author: jloor@illinois.edu cesses," "organismal systems," and "diseases" were activated by putative target genes of miR-31and miR-16a, with an overlapping activation of "immune system" and "signal transduction." A pronounced effect and activation of miR-31 target genes was observed within "folding, sorting, and degradation," "cell growth and death," and "cell communication" pathways, whereas a marked inhibition of "lipid metabolism" occurred. Putative targets of miR-181a had a strong effect on Fc $\gamma$ R-mediated phagocytosis, toll-like receptor signaling, and antigen processing and presentation, which were activated during intramammary infections. The targets of both miR-31 and miR-223 had an inhibitory effect on "lipid metabolism." Overall, the combined analyses indicated that changes in mammary tissue immune, metabolic, and cell growth-related signaling pathways during infection might have been mediated in part through effects of miRNA on gene transcription. Differential expression of miRNA supports the view from nonruminant cells/tissues that certain miRNA might be essential for the tissue's adaptive response to infection.

Key words: microRNA, bovine, mammary epithelial cell

\section{INTRODUCTION}

Mastitis is a persistent, inflammatory response of mammary tissue attributed to intramammary invasion of a mastitis-causing pathogen such as Streptococcus uberis (Rinaldi et al., 2010). This potentially fatal infectious challenge is the most common disease in dairy cattle in the United States (Bar et al., 2008; Harmon, 1994). To effectively control mastitis pathogens, it is important to understand the mechanism controlling the immune response at the molecular level (Rinaldi et al., 2010).

Recent reviews of the literature over the last decade have examined the mammary transcriptome in response to mastitis infection with different pathogens (Rinaldi et 
al., 2010) and bioinformatics approaches for data mining in a more holistic fashion (Loor et al., 2011). From that standpoint, it is well established in nonruminants that several microRNA (miRNA) play important functional roles across a wide spectrum of physiological and pathological processes (Tili et al., 2008; Kim et al., 2009). These molecules are single-stranded noncoding RNA of 19 to 23 nucleotides that regulate the gene expression mainly at the posttranscriptional level. They may inhibit translation or destabilize the target RNA. Exploring the adaptations of mammary cell miRNA during mastitis would provide an additional level of understanding that could help explain the response of mammary epithelial cells to infection.

The recently identified miR-146, -181a, -151, -31, $-223,-145$, and -155 are known to regulate various biological pathways including immunity (Johnnidis et al., 2008), development and function of immune components (Johnnidis et al., 2008), and response to microbial infection (Taganov et al., 2006). For instance, the expression of miR-146 and miR-155 in B and $\mathrm{T}$ lymphocytes is induced in response to microbial infection (Eis et al., 2005; Taganov et al., 2006; Tam and Dahlberg, 2006). By inhibiting the expression of the immune-related genes SPI1 (Vigorito et al. 2007), SOCS1 (Lu et al., 2009), and SHIP1 (O'Connell et al., 2009), miR-155 plays important biological roles in different physiological conditions (e.g., its target, SHIP1, plays a role in activating AKT-dependent cellular events in rat mammary epithelial cells; Su et al., 2007). In addition, miR-16a regulates immunity by inhibiting the production of inflammatory mediators through degradation, thus helping to reduce their level after inflammation in most nonruminant cell types (Jing et al., 2005). All of the above evidence suggests that certain miRNA might be particularly important in the modulation of immune response in mammary cells.

Each miRNA targets many genes; thus, the regulatory networks regulated by these molecules are likely to be substantial (Lewis et al., 2003) and may affect the cell's response to bacterial infection (i.e., apoptosis induction, adhesion and killing of invading bacteria, and cell tropism to bacteria in mammary epithelial cells; Wesson et al., 2000; Hensen et al., 2000). The general hypothesis of the present study was that expression of immune-related miRNA is altered by intramammary Strep. uberis infection, just as we observed for the transcriptome (Moyes et al., 2009a). Specific objectives were to determine differential expression of selected miRNA, link the selected miRNA with their target genes in the microarray data set, and use bioinformatics to uncover the most affected pathways and functions within the data.

\section{MATERIALS AND METHODS}

\section{miRNA Extraction, PCR, and Design and Evaluation of Primers}

Details of the management of cows, experimental design, and tissue biopsy have been published in detail (Moyes et al., 2009a,b). Briefly, 10 multiparous cows past peak lactation ( $>60 \mathrm{~d}$ postpartum) with composite milk SCC $<200,000$ cells $/ \mathrm{mL}$ were used. Biopsies of mammary tissue from both rear quarters of all cows (i.e., infected and noninfected quarters) were obtained $20 \mathrm{~h}$ postchallenge. Tissue used in this study was the same as those used for transcriptomics (Moyes et al., 2009a). Total RNA was extracted from mammary tissue using the mirVana miRNA isolation kit (AM1561; Life Technologies Corp., Carlsbad, CA). One hundred milligrams of mammary tissue was homogenized in $10 \mathrm{vol}$ of mirVana Lysis/Binding Solution using a Tissue-Tearor (BioSpec Products Inc., Bartlesville, OK) homogenizer at maximum speed. Then one-tenth volume of miRNA homogenate additive was added, mixed thoroughly by vortexing for $30 \mathrm{~s}$, and incubated on ice for $10 \mathrm{~min}$. An equal volume of acid-phenol:chloroform (Life Technologies Corp.) was then added to each aliquot. The resulting solution was mixed by vortexing for $1 \mathrm{~min}$ and centrifuged for $5 \mathrm{~min}$ at $10,000 \times g$ at room temperature $\left(\sim 23^{\circ} \mathrm{C}\right)$. The aqueous phase was carefully removed and then mixed thoroughly with 1.25 volumes of $100 \%$ ethanol and passed through a mirVana Filter Cartridge in sequential $700-\mu \mathrm{L}$ aliquots. The filter cartridge was washed according to the manufacturer's protocol and RNA was eluted in nuclease-free water at $95^{\circ} \mathrm{C}$. Purity of RNA was assessed via a ratio of $260 / 280$ using a NanoDrop ND-1000 spectrophotometer (NanoDrop Technologies Inc., Rockland, DE).

Details on PCR and design and evaluation of primers are reported in the Supplementary File (available online at http://www.journalofdairyscience.org/). Briefly, mammary tissue samples (Moyes et al., 2009a) were used for extraction of total RNA and enrichment of miRNA using a miRNA isolation kit. Quantitative PCR was performed using the NCode miRNA First-Strand Synthesis and quantitative real-time PCR (qRT-PCR) kits (MIRC10; Life Technologies Corp.), according to the manufacturer's protocol. The reactions were performed in an ABI Prism 7900 HT Sequence Detection Systems (SDS) instrument (Applied Biosystems Inc., Foster City, CA), and the data calculated with the 7900 HT Sequence Detection Systems Software (version 2.2.1; Applied Biosystems Inc.). The quantitative PCR performance data and sequence and primer information of U6 and small nucleolar RNA (snoRNA) are provided 
in the Supplemental File (available online at http:// www.journalofdairyscience.org/).

\section{Bioinformatics Analysis}

Identification of putative target genes among differentially expressed genes [DEG; a total of 2,102 with unique Bos taurus gene identifications (ID)] due to Strep. uberis infection (Moyes et al., 2009a) for all of the miRNA studied was performed using the web-based software package Ingenuity Pathway Analysis (IPA; Ingenuity Systems Inc., Redwood City, CA). Each miRNA studied was assigned its corresponding B. taurus gene and miRBase ID before analysis against the bovine $3^{\prime}$ untranslated region ( $3^{\prime}$ UTR) in the list of DEG. The IPA tool has a miRNA target filter function that relies on experimentally validated interactions from the TarBase database (Vergoulis et al., 2012), miRecords (http://mirecords.biolead.org/), TargetScan (http:// www.targetscan.org/), and manually curated miRNArelated findings within the IPA knowledgebase. The latter pertains exclusively to information in the published scientific literature, whereas the first 3 methods rely on text mining-assisted curation (TarBase) or algorithms (TargetScan and miRecords) that find mRNA targets by searching for the presence of conserved 8 mer $(\geq 0.8$ conserved branch length) and 7 mer sites that match the seed region of each miRNA. The total number of upregulated and downregulated target DEG is shown in Supplementary Table 3 (available online at http:// www.journalofdairyscience.org/). The complete list is found in Supplementary Table 4 and a partial list is shown in Figure 1.

Bioinformatics analysis to identify affected pathways, biological processes, and molecular functions within the DEG and the respective miRNA was performed using a novel approach we developed (dynamic impact approach, DIA) and have described previously (Bionaz et al., 2012). Briefly, the entire microarray data set with associated statistical $P$-values were imported into IPA, The Database for Annotation, Visualization and Integrated Discovery (DAVID version 6.7; http:// david.abcc.ncifcrf.gov/) and Kyoto Encyclopedia of Genes and Genomes (KEGG) software (http://www. genome.jp/kegg/). Entrez gene ID were used to identify individual sequences. The "Impact" refers to the absolute perturbation in a biological process (i.e., overall dynamics within a term/pathway). It gives the magnitude of changes that occur (due to treatment) within a pathway/function in either direction weighted by the percent DEG that hit the term/pathway. The "Flux" refers to the overall direction in which a term/pathway is impacted after treatment (Bionaz et al., 2012; i.e., "activation" or "inhibition"). The length of the bars depicts the degree of the impact, and the intensity of the color (e.g., from dark green denoting highly downregulated to dark red denoting highly upregulated) was used to highlight the degree of activation or inhibition of pathways and terms. The entire KEGG and DAVID analysis can be found in Supplementary Tables 5 to 12 (available online at http://www.journalofdairyscience. org/).

\section{RESULTS AND DISCUSSION}

Details on local and systemic responses to IMI challenge with Strep. uberis are described elsewhere (Moyes et al., 2009b). All cows developed signs of mastitis. A complete list of the target genes of all selected miRNA among the 2,102 DEG found in the microarray is provided in Supplementary Table 4 (available online at http://www.journalofdairyscience.org/). Inhibition and activation of many physiologically relevant pathways was revealed using the DIA. The complete bioinformatics analysis using KEGG on target genes of each miRNA is provided in Supplementary Tables 5 to 11 (available online at http://www.journalofdairyscience.org/), and the top 25 categories from the DAVID analysis for each miRNA studied can be found in Supplementary Table 12. Among affected miRNA (Table $1 ; P \leq 0.07$ ), only miR-223 was upregulated, whereas miR-16a, -31, and -181a were downregulated in infected versus healthy mammary tissue. From the current bioinformatics analysis it was evident that immune- and cell survivalrelated pathways were the most impacted; thus, they are the focus of the discussion.

\section{$\operatorname{miR}-16 a$}

The expression of miR-16a was lower $(P<0.05)$ in mammary tissue challenged with Strep. uberis (Table 1). Relative to other miRNA studied, the target genes of miR-16a that were affected by IMI resulted in a clear impact and overall induction of "lipid metabolism," "signal transduction," and "immune system" (Figure 1). In particular, "TGF-beta signaling" was clearly activated by the lower expression of miR-16 and alterations in its target genes. The miR-16a is expressed at high levels in most nonruminant cells and tissues studied to date (Landgraf et al., 2007). A key function of miR-16a is to prevent cell cycle progression (Linsley et al., 2007) and maintain the level of inflammatory mediators in cells to regulate immunity after an infection (Jing et al., 2005). Expression of miR-15b and IL6 were markedly upregulated in macrophages in response to a proinflammatory challenge (Dave and Khalili, 2010). The miR- 


\begin{tabular}{|c|c|c|c|c|c|}
\hline Category & miR-31 & miR- 145 & miR-181a & miR-223 & miR-15b/16a \\
\hline 1. Metabolism & & 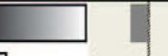 & & = & \\
\hline 0.1 Metabolic Pathways & & & 」 & & $\square$ \\
\hline 1.1 Carbohydrate Metabolism & & & & & \\
\hline 1.2 Energy Metabolism & & & $\square$ & & \\
\hline 1.3 Lipid Metabolism & & & & & \\
\hline 1.4 Nucleotide Metabolism & & & & & \\
\hline 1.5 Amino Acid Metabolism & & & & & \\
\hline 1.6 Metabolism of Other Amino & & & & & \\
\hline 1.7 Glycan Biosynthesis and Meta & & & & & \\
\hline 1.8 Metabolism of Cofactors and & & & 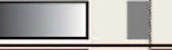 & 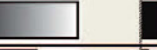 & \\
\hline 2. Genetic Information Processin & & & 7 & & \\
\hline 2.1 Transcription & & & & & \\
\hline 2.3 Folding, Sorting and Degradat & & & & & $\square$ \\
\hline 2.4 Replication and Repair & & & & & \\
\hline 3. Environmental Information Pro & & & & & L \\
\hline 3.1 Membrane transport & & & & & \\
\hline 3.2 Signal Transduction & & & & & \\
\hline 3.3 Signaling Molecules and Inter & & & & & \\
\hline 4. Cellular Processes & & 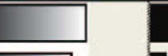 & & & L \\
\hline 4.1 Transport and Catabolism & & & & & \\
\hline 4.2 Cell Motility & & 」 & - & & \\
\hline 4.3 Cell Growth and Death & & & 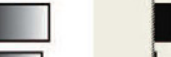 & & 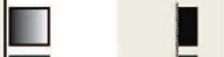 \\
\hline 4.4 Cell Communication & & & $\square$ & & $\square$ \\
\hline 5. Organismal Systems & & & & & $\square$ \\
\hline $5.1 \mathrm{Immune}$ System & & & & & \\
\hline 5.2 Endocrine System & & & & & $\square$ \\
\hline 5.3 Circulatory System & & & $\square$ & & \\
\hline 5.4 Digestive System & & 7 & 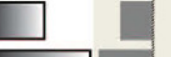 & & \\
\hline 5.5 Excretory System & & & & & \\
\hline 5.6 Nervous System & & 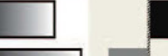 & 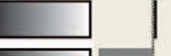 & & $\square$ \\
\hline 5.8 Development & & & & & \\
\hline 5.9 Environmental Adaptation & & & & & \\
\hline 6. Human Diseases & & & & & $\square$ \\
\hline 6.1 Cancers & & & & & $\square$ \\
\hline 6.2 Immune System Diseases & & & & & \\
\hline 6.3 Neurodegenerative Diseases & & & & & \\
\hline 6.4 Cardiovascular Diseases & & & & & \\
\hline 6.5 Metabolic Diseases & & & & & \\
\hline 6.6 Infectious Diseases & & 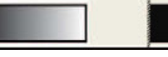 & 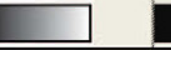 & & $\square$ \\
\hline
\end{tabular}

Figure 1. Kyoto Encyclopedia of Genes and Genomes (KEGG; http://www.genome.jp/kegg/) categories uncovered by the dynamic impact approach (DIA) analysis using differentially expressed genes (DEG) that are putative targets of miR-31, $-145,-181 \mathrm{a},-223$, and $-15 \mathrm{~b} / 16 \mathrm{a}$. Shown are the overall impact (left column) and flux (right shaded column) of the pathways for microRNA (miRNA). For interpretation of flux, gray horizontal bars (increasing toward the left) denote inhibition and black horizontal bars (increasing toward the right) denote activation. The length of the bar in the left column denotes the extent of the impact. Color version available in the online PDF. 
Table 1. Expression of microRNA (miRNA; log-transformed data) in healthy or Streptococcus uberis-infected mammary tissue from lactating Holstein cows

\begin{tabular}{|c|c|c|c|c|}
\hline \multirow[b]{2}{*}{ miRNA } & \multicolumn{2}{|c|}{ Infection status } & \multirow[b]{2}{*}{ SEM } & \multirow[b]{2}{*}{$P$-value } \\
\hline & Infected & Healthy & & \\
\hline miR-10a & -0.77 & -0.28 & 0.23 & 0.16 \\
\hline miR-15b & -1.52 & -0.45 & 0.44 & 0.09 \\
\hline miR-16a & -0.60 & -0.27 & 0.07 & 0.01 \\
\hline miR-17 & -1.43 & -0.80 & 0.80 & 0.56 \\
\hline miR-21 & -1.01 & -0.65 & 0.53 & 0.64 \\
\hline miR-31 & -0.78 & -0.17 & 0.22 & 0.07 \\
\hline miR-145 & -1.02 & -0.29 & 0.28 & 0.09 \\
\hline miR-146a & -0.76 & -0.40 & 0.53 & 0.64 \\
\hline miR-146b & -0.51 & -0.25 & 0.17 & 0.31 \\
\hline miR-155 & -1.31 & -0.79 & 0.58 & 0.53 \\
\hline miR-181a & -5.87 & -2.24 & 1.30 & 0.05 \\
\hline miR-205 & -2.07 & -2.02 & 0.36 & 0.94 \\
\hline miR-221 & -2.72 & -2.32 & 0.36 & 0.45 \\
\hline miR-223 & -0.64 & -1.54 & 0.12 & 0.01 \\
\hline
\end{tabular}

16a degrades tumor necrosis factor (TNF), IL8, and IL6 by acting on their $3^{\prime}$ UTR after infection (Jing et al., 2005). All of these major cytokines (including IL10) are targets of miR-16a in our bioinformatics analysis (Table 2).

From the available evidence it can be speculated that lower expression of miR-16a due to IMI might have allowed for greater mRNA expression of IL 8 (infected vs. healthy fold change $=1,054)$, IL6 (fold change $=430)$, and $I L 10$ (fold change $=\sim 28$ ) before peak clinical signs of mastitis (Moyes et al., 2009a). Interleukin-8 is an important component of the innate immune response and is involved in chemotaxis of polymorphonuclear leukocytes. A greater expression of $I L 8$ in mammary epithelial cells in response to $E$. coli infection was observed previously (Günther et al., 2009). Interleukin-10 is an antiinflammatory cytokine and suppresses the production of other inflammatory cytokines such as TNF, IL1, and IL6 by blocking nuclear factor $\kappa \beta$ (NFk $\beta$ ). Thus, it seems logical that a lower expression of miR-16a (and also miR-15b) would occur before peak clinical signs of mastitis.

Our data suggested that miR-16a in bovine mammary tissue might control the level of key inflammatory components. As such, it would play both a direct and indirect role in regulating the appropriate response to an IMI. Despite this seemingly important role during mastitis infection, the marked upregulation of these proinflammatory signals and TLR2 (Moyes et al., 2009a) also suggest that potential counterregulatory mechanisms to control overt inflammation might have been curtailed (i.e., upregulation of miR-146a is key in the control of inflammation; Nahid et al., 2011) but was not affected by IMI (Table 1 ). We speculate that the high dose of Strep. uberis used might have overwhelmed the molecular systems controlling inflammation.

Table 2. Subset of target genes $(P \leq 0.01)$ of microRNA (miRNA) among previously identified differentially expressed genes (DEG; Moyes et al., 2009a) $)^{1}$

\begin{tabular}{|c|c|c|}
\hline miRNA & Upregulated & Downregulated \\
\hline $\mathrm{miR}-15 \mathrm{~b} / 16 \mathrm{a}$ & $\begin{array}{l}\text { SLC30A4, FASN, BTN1A1, UBE2Q1, ADRB2, FOS, IL6, IL10, } \\
\text { IL10RB, IL18, LYZ, TNF, IL8 }\end{array}$ & $\begin{array}{l}\text { FGF7, NOB1, IL10RA, ACSL5, TFPI2, HSPA8, } \\
\text { ARRDC4, PPAP2B, CD69, BTG2, SLC2A3 }\end{array}$ \\
\hline miR-17 & $\begin{array}{l}\text { MEF2C, SSH2, FGL2, STAT3, LTV1, MAP3K8, CX3CL1, FGF, } \\
\text { MPZL2, HSPA8, THBS1, CASP4, NR 4A3, MXD1, CXCL6, } \\
\text { CD69, IL8, SOD2, LDLR }\end{array}$ & $\begin{array}{l}\text { LPIN1, IGF2BP2, BTN1A1, ZBTB38, MGEA5, } \\
\text { GPAM, AAK1, C5orf13, CLSTN1 }\end{array}$ \\
\hline miR-31 & $\begin{array}{l}\text { ITGAV, FGF', CALR, TMEM49, CD55, CTSC, HIF1A, } \\
\text { TWISTNB }\end{array}$ & LPIN1, BTN1A1 \\
\hline miR-145 & $\begin{array}{l}\text { SSH2, DLC1, NOLC1, PRKX, CXCR2, MPZL2, ACTG1, } \\
\text { VCAM1, DNAJB11, ZFP36, NR4A3, TNFAIP2, FSCN1 }\end{array}$ & FAM $55 C$ \\
\hline $\operatorname{miR}-146 a / b$ & $\begin{array}{l}\text { SOCS3, CKAP4, ARID3A, ERRFI1, SDCBP, BTG2, IL8, CTSC, } \\
\text { SLC2A3, IL10, IL10RB, LDLR, TNF }\end{array}$ & DNAJC12, C5orf13, TNFAI P8, DLC1 \\
\hline miR-155 & $\begin{array}{l}\text { SSH2, FGL2, FGF\%, F13A1, ACSL5, PHC2, SPI1, FO, SDCBP, } \\
\text { C14orf147, IL6, BIRC3, FOS, IL18, LTF, TNF }\end{array}$ & $\begin{array}{l}\text { CD 36, FZD5, ZBTB38, C12orf65, AAK1, } \\
\text { TNFAIP8 }\end{array}$ \\
\hline $\operatorname{miR}-221$ & $\begin{array}{l}\text { SOD2, C14orf147, SDCBP, FOS, ZFP36, PPAP2B, THBS1, } \\
\text { ARRDC4, MARCKS, HSPA8, SOCS3 }\end{array}$ & TPD52L1, AAK1, GPAM, IGF2BP2 \\
\hline $\operatorname{miR}-223$ & $M E F 2 C, I L 6, L Y Z, T N F$ & TRAF3IP3, C12orf65, CLSTN1, LPL, IGF1R \\
\hline miR-205 & PEG3, ZBTB38, GPAM, AAK1, CD24, TNFAIP8 & DLC1, IL15RA, PHC2, MARCKS, ERRFI1 \\
\hline
\end{tabular}

\footnotetext{
${ }^{1} \mathrm{~A}$ full list of target genes is reported in the Supplementary Material (available online at http://www.journalofdairyscience.org/).
} 


\section{$\operatorname{miR}-223$}

The miR-223 was the only upregulated miRNA in response to IMI (Table 1). This miRNA has been studied primarily in granulocytes and neutrophils (Johnnidis et al., 2008) and bovine blood monocytes (Dilda et al., 2012). A previous study observed no changes in miR223 expression in bovine blood monocytes challenged for $14 \mathrm{~h}$ with a small dose (100 ng) of Strep. aureus enterotoxin B and E. coli (Dilda et al., 2012). In addition to its upregulation, target genes of miR-223 exhibited different behavior in the bioinformatics analysis relative to responses found with other miRNA targets. Using the DIA with KEGG (Figure 1; Supplementary Tables, available online at http://www.journalofdairyscience. org/) revealed an overall inhibition of "organismal systems" (Supplementary Table 10) including inhibition of "immune system" (several signaling pathways), "endocrine system" (e.g., insulin signaling), "excretory system," and "nervous system." Within "human diseases" (Supplementary Table 11), analysis revealed that an overall inhibition of "infectious" (e.g., bacterial invasion of epithelial cells) and "metabolic" diseases. Within "metabolism" (Supplementary Table 6), "lipid metabolism" (e.g., sphingolipid metabolism) and "metabolism of cofactors and vitamins" (nicotinamide metabolism) were inhibited and "nucleotide metabolism" (purine metabolism) and "folate metabolism" were activated (Figure 1; Supplementary Table 6, available online at http://www.journalofdairyscience.org/). Within "cellular processes" (Supplementary Table 9) only "transport and catabolism" of lysosome was activated by miR-223, whereas "endocytosis" and "peroxisome" were the most impacted and inhibited.

Previously reported roles of miR-223 include negative regulation of neutrophil proliferation, granulocyte differentiation, and inhibition of cell cycle progression via downregulation of elongation factor E2F (Fazi et al., 2005; Johnnidis et al., 2008). Expression of miR-223 is partly controlled by $\mathrm{C} / \mathrm{EBP} \alpha$ (CCAAT enhancer-binding factor) and NF1-A (a transcription factor of the CCAAT family; Fazi et al., 2005). In human granulocytes, $\mathrm{C} / \mathrm{EBP} \alpha$ activates the transcription of miR-223 and NF1-A inhibits its transcription by binding to the promoter (Fazi et al., 2005). The effects of $\mathrm{C} / \mathrm{EBP} \alpha$ on inhibition of cellular proliferation are mediated by directly inhibiting cyclin-dependent kinases (CDK2 and CDK4) or by inducing miR-223 expression to block E2F2 (Fazi et al., 2005). In addition, in cultured macrophages, C/EPB was shown to be a direct target of miR-155 (Worm et al., 2009). Although miR-155 was not differentially expressed in our study, the upregulation of isoforms of $C / E P B[C /$ $E B P D$ (1.97-fold change, infected vs. control) and $C$ /
EBPB (1.27-fold change; Moyes et al., 2009a)] might have been partly responsible for the greater expression of miR-223 in mammary tissue. In addition, miR-223 also enhances its own expression indirectly by inhibiting the expression NF1A (Fazi et al., 2005). The inhibition of various signaling pathways containing targets of miR-223 (Figure 2), suggesting that $C E B P$ might play an important regulatory role in mammary adaptations to infection via miR-223.

Of all signaling pathways associated with targets of miR-223 within "environmental information and processing" (Supplementary Table 8, available online at http://www.journalofdairyscience.org/), Notch and mitogen-activated protein kinase (MAPK) were highly affected and activated with IMI (Figure 2). In contrast, ECM-receptor interaction, vascular endothelial growth factor (VEGF) signaling, epidermal growth factor receptor (ErbB) signaling, transforming growth factor $\beta$ (TGF- $\beta$ ) signaling, and cell adhesion molecules (CAM) were highly impacted but inhibited (Figure 2). Although cytokine-cytokine receptor interaction was highly impacted, the overall flux was only modestly activated. Within "organismal system" (Supplementary Table 10, available online at http:// www.journalofdairyscience.org/), RIG-I-like receptor signaling was the most impacted and inhibited (Figure 2). Only NOD-like receptor signaling was activated by alterations in miR-223 targets but the overall impact was low compared with RIG-I-like receptor signaling. These results revealed that among all tested miRNA, only miR-223 altered Notch signaling (i.e., this pathway might be specifically regulated by target genes with altered expression in response to Strep. uberis).

Notch signaling plays a critical role in steering an immune response toward inflammation by regulating the expression of various proinflammatory cytokines, which in turn, activate the pathway further (Benson et al., 2004). From that standpoint, the discovery that miR223 upregulation during IMI led to an activation of "leukemia inhibitory factor receptor binding" and "interleukin-12 receptor binding" (Supplementary Table 12, available online at http://www.journalofdairyscience. org/) appears to confirm previous observations from the murine mammary gland, which underscored that the mammary tissue is immune responsive (Clarkson et al., 2004; Piantoni et al., 2010). The gene ontology (GO) analysis using the DIA (Supplementary Table 12) further highlighted a potential key role of miR223 in bovine mammary epithelial cells (i.e., "inhibin binding," "insulin binding," "activin receptor activity," "folic acid binding," and "thyroxine 5'-deiodinase activity" were markedly inhibited. Several of those biological processes have been previously shown to play important roles in bovine mammary tissue metabolism 


\begin{tabular}{|c|c|c|c|c|c|}
\hline Immune System & miR-31 & miR-145 & miR-181a & miR-223 & miR-15b/16a \\
\hline NOD-like receptor signaling pathway & & & & & \\
\hline Fc gamma R-mediated phagocytosis & & & & & \\
\hline Toll-like receptor signaling pathway & & & & & \\
\hline B cell receptor signaling pathway & & & & & \\
\hline Antigen processing and presentation & & & & & \\
\hline RIG-I-like receptor signaling pathway & & & & & \\
\hline Leukocyte transendothelial migration & & & & & \\
\hline Chemokine signaling pathway & & & $\square$ & & \\
\hline Hematopoietic cell lineage & & & & & \\
\hline Natural killer cell mediated cytotoxicity & & & & & \\
\hline T cell receptor signaling pathway & & & & & \\
\hline Fc epsilon RI signaling pathway & & & & & \\
\hline Intestinal immune network for IgA production & & & & & \\
\hline Cytosolic DNA-sensing pathway & & & & & \\
\hline Complement and coagulation cascades & & 1 & & & \\
\hline Environmental Information Processing & & & & & \\
\hline mTOR signaling pathway & & & & & $\square$ \\
\hline TGF-beta signaling pathway & & & & & \\
\hline Jak-STAT signaling pathway & & & & & \\
\hline Cytokine-cytokine receptor interaction & & & 1 & & \\
\hline MAPK signaling pathway & & & 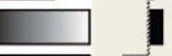 & & $\square$ \\
\hline ECM-receptor interaction & & & $\square$ & & \\
\hline VEGF signaling pathway & & & & & \\
\hline Wnt signaling pathway & & & & & L \\
\hline$A B C$ transporters & & & & & \\
\hline Cell adhesion molecules (CAMs) & & & & & \\
\hline ErbB signaling pathway & & & 4 & & \\
\hline Hedgehog signaling pathway & & & & & $\square$ \\
\hline Neuroactive ligand-receptor interaction & & & & & \\
\hline Calcium signaling pathway & & & & & \\
\hline Phosphatidylinositol signaling system & & & & & \\
\hline Notch signaling pathway & & & & & \\
\hline Genetic Information Processing & & & & & \\
\hline SNARE interactions in vesicular transport & & & & & \\
\hline Protein export & & & & & \\
\hline Protein processing in endoplasmic reticulum & $\square$ & $\square$ & $\square$ & & $\square$ \\
\hline Ubiquitin mediated proteolysis & & $\square$ & 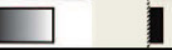 & & \\
\hline
\end{tabular}

Figure 2. Kyoto Encyclopedia of Genes and Genomes (KEGG; http://www.genome.jp/kegg/) pathway results for the most-impacted categories within "organismal systems," "environmental information processing," and "genetic information processing" uncovered by the dynamic impact approach (DIA) analysis using differentially expressed genes (DEG) that are putative targets of miR-31, $-145,-181 \mathrm{a},-223$, and $-15 \mathrm{~b} / 16 \mathrm{a}$. Shown are the overall impact (left column) and flux (right shaded column) of the pathways for microRNA (miRNA; $P<0.10)$. For interpretation of flux, gray horizontal bars (increasing toward the left) denote inhibition and black horizontal bars (increasing toward the right) denote activation. The length of the bar in the left column denotes the extent of the impact. Color version available in the online PDF.

and development (Phillips, 2005; Capuco et al., 2008; Menzies et al., 2009).

From a mechanistic standpoint, the inhibition of several cellular signaling pathways (e.g., TGF- $\beta$, ECMreceptor interaction, ErbB, and phosphatidylinositol;
Figure 2) by upregulation of miR-223 might have been mediated in part via downregulation of $I G F 1 R$ (Figure 1 ), which is required for IGF-1 signaling and enhances bactericidal activity of neutrophils (Inoue et al., 1998). Although we did not measure serum IGF-1 in these 
cows, the increase in serum insulin concentration postIMI challenge (Moyes et al., 2009b) and the inhibition of "insulin binding" (Supplementary Table 12, available online at http://www.journalofdairyscience.org/) could be taken as an indication of reduced mammary sensitivity to anabolic hormones including IGF-1. Overall, the inhibition of "insulin binding" and IGF1R agreed with our previous analysis using IPA demonstrating an inhibition of IGF-1 signaling with IMI (Moyes et al., 2009a); however, an additional regulatory role of miRNA was revealed by the current integrative approach (i.e., components of this pathways such as protein kinase C, IGF2BP2, and IGFBP5 are targets of several miRNA: miR-17, miR-221, and miR-223).

Insulin-like growth factor 1 signaling is not only involved in synthesis of milk protein but also plays a crucial role in maintaining the integrity of mammary epithelial tissue (Bionaz and Loor, 2011), thus underscoring its importance during lactation. In addition, by delaying the apoptotic response of resident neutrophils (Himpe et al., 2008) IGF-1 signaling mediated through the PI3K/AKT pathway (Popova et al., 2009) confers resistance (i.e., increased survival during infection) to mammary epithelial cells against infection. The inhibition of the pathway (Moyes et al., 2009a) strongly suggests a weakening of epithelial cells after infection. A compromised integrity of epithelial cells followed by shedding might be associated with the inhibition of the aforementioned pathways. If that holds true in mammary tissue after IMI, our data suggest that apoptosis of neutrophils was probably substantial at $20 \mathrm{~h}$ after inoculation (Moyes et al., 2010).

A potentially negative modulation of the mammary tissue immune response (i.e., dysregulation) by miR223 upregulation was underscored in the current study by the observed inhibition of "Fc $\gamma R$-mediated phagocytosis," "leukocyte transendothelial migration," "natural killer cell mediated cytotoxicity," "T cell receptor signaling," and "RIG-I like receptor signaling." An inhibition of the latter, in particular, might have negative consequences in terms of the mammary cell's ability to produce antiviral cytokines (Bruns and Horvath, 2012) that may be functional during IMI. From a biological standpoint, a negative modulation of immune response might be required during inflammation in mammary cells to avoid damage to host tissue (Lindsay, 2008). The lack of change in miR-146a coupled with the marked upregulation of TLR2 (Moyes et al., 2009a) underscored the existence of dysregulation during IMI because miR-146a is a key controller of the inflammatory response (Nahid et al., 2011). A deeper analysis of the biological functions and effects of the expression of miR-223 in mammary epithelial cells is needed to clarify the exact link between our observations and the disease.

\section{miR-181a}

A lower expression of miR-181a $(P<0.05)$ in response to IMI was observed in this study. A list of miR-181a target genes affected by IMI is shown in the Supplementary Material (available online at http:// www.journalofdairyscience.org/). The lower miR-181a expression was associated with activation of $\mathrm{Fc} \gamma \mathrm{R}$ mediated phagocytosis, toll-like receptor (TLR) signaling, B cell receptor signaling, antigen processing and presentation, protein export, protein processing in the endoplasmic reticulum (ER), and ubiquitin-mediated proteolysis (Figure 2; Supplementary Tables 10 and 11, available online at http://www.journalofdairyscience. org/). All of these have clear roles in the immune system response to IMI. Among signaling pathways unrelated to immune system per se, we observed that TGF- $\beta$, Janus kinase-signal transducer and activator of transcription (JAK-STAT), MAPK, Wnt, and ABC transporter signaling were highly affected and activated (Figure 2). Additional GO analysis using the DIA revealed non-immune-related functions affected by genes under partial control of miR-181a (e.g., "lipid phosphatase activity," "glucose transmembrane transport," "tRNA methyltransferase activity," and "stearoyl-CoA desaturase activity"; Supplementary Table 12, available online at http://www.journalofdairyscience.org/). Interestingly, just as was the case with miR-223, highly affected GO functions included "leukemia inhibitory factor activity" and "inhibin binding."

Toll-like receptor signaling is a major player of immune activation after infection, and leads to synthesis of proinflammatory cytokines (e.g., TNF, IL1B, and IL6). Lipopolysaccharide from gram-negative bacteria stimulates the TLR4 signaling pathway and is a key mediator of innate immunity. Prior work has revealed the upregulation of TLR4, FOS, IL8, and IL6 in mammary tissue after IMI challenge with gram-positive bacteria (Lutzow et al., 2008). The TLR pathway was induced in our analysis by all differentially expressed miRNA but the strongest activation was observed for miR-181a (Figure 2; Supplementary Table 10, available online at http://www.journalofdairyscience.org/). A stronger activation with miR-181a also was observed for protein export and protein processing in the ER ("genetic information processing"), both of which might be related to the proinflammatory cytokine response. Among several genes of the TLR pathway upregulated during IMI challenge (Moyes et al., 2009a), the IPA analysis revealed 2 targets of miR181a (i.e., TLR4 
and FOS; Table 2), which had greater expression after IMI and support the involvement of inflammation and apoptosis during the process of tissue remodeling as a result of inflammation (Clarkson et al., 2004).

Our results suggest that miR-181a could regulate proinflammatory genes within the TLR signaling pathway during mastitis. It also is possible that TLR signaling during infection of the mammary gland induces other miRNA that exert control on the expression of genes composing the pathway (e.g., TLR4 activation was more effective than TLR2 or TLR3 in upregulating miR-147 expression, which subsequently led to upregulation of TNF; Liu et al., 2009). Although not affected in our study, miR-146a is key for controlling TLR2 and TLR4 signaling (i.e., it operates as negative feedback mechanism to prevent uncontrolled inflammation; Nahid et al., 2011). Thus, the fact that both TLR2 and TLR 4 were upregulated due to IMI (Moyes et al., 2009a) underscores a potentially important role of miRNA networks in controlling local inflammation. Our data on TLR2 and miR-146a would suggest that the miRNA control mechanisms might have been impaired by the dose of Strep. uberis.

A role in T-cell differentiation (Chen et al., 2004) and T-cell receptor (TCR) signaling sensitivity (Li et al., 2007) has been demonstrated for miR-181a. The TCR signaling and antigen processing and presentation pathways involve phosphorylation and dephosphorylation events. The miR-181a increases $\mathrm{T}$ cell strength and sensitivity by downregulating the mRNA and protein expression of non-receptor-type tyrosine phosphatases (PTPN) or dual-specificity phosphatases [DUSP; extracellular regulated kinase (ERK) dephosphorylation] that negatively regulate TCR signaling ( $\mathrm{Li}$ et al., 2007). The bioinformatics analysis supports a role for miR-181a in the control of phosphatase and transport activity (Supplementary Table 12, available online at http://www.journalofdairyscience.org/) in mammary tissue. In the former, downregulation with IMI might have enhanced sensitivity to specific signaling cues, whereas the enhanced transport activity might have been related in part with glucose use by immune and mammary epithelial cells.

The activation of the JAK-STAT signaling pathway by miR-181a also was a unique feature, as it had a large impact relative to other miRNA (Figure 2). Leukemia inhibitory factor (LIF) activates the JAK-STAT and MAPK pathways in nonruminant cells (Kunisada et al., 1996). The former is known to regulate the phosphatidylinositol pathway in the mouse mammary gland (Abell and Watson, 2005), partly by controlling inflam-

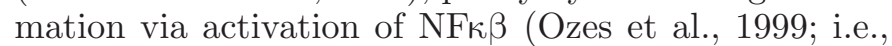
LIF mRNA is upregulated in various inflammatory conditions; Szepietowski et al., 2004). From a mecha- nistic standpoint the high impact and degree of activation of LIF receptor binding (Supplementary Table 12, available online at http://www.journalofdairyscience. org/) by miR-223 and miR-181a is a remarkable feature because of the divergent response of these miRNA to IMI (i.e., one was upregulated, whereas the other one was downregulated). However, this probably is not surprising, given the overlap in target genes by several miRNA (Supplementary Table 4). In murine mammary epithelial cells the induction of LIF expression is necessary for cellular apoptosis (Schere-Levy et al., 2003) and might have contributed (Zhao and Lacasse, 2008) to increasing that process during IMI in our study. The regulation of a wide range of phosphatases ( $\mathrm{Li}$ et al., 2007) and the T cell sensitivity (Chen et al., 2004) to antigens underscores the role of miRNA in regulating proinflammatory responses in mammary epithelial cells.

\section{$\operatorname{miR}-31$}

In our study, miR-31 was downregulated $(P=0.07)$ in response to infection (Table 1). The high impact and marked induction of "cancer" revealed by KEGG analysis (Figure 1) underscored an association of miR31 with cellular survival and death pathways (Wnt and MAPK signaling), including vascularization (e.g., VEGF signaling; Figure 2). Interestingly, mammalian target of rapamycin (mTOR) signaling also was highly affected but was the only one inhibited by differential expression of miR-31 targets. Additional pathways that were highly affected and activated by miR-31 target genes were soluble NSF attachment protein receptor (SNARE) complex and protein processing in the ER. Recent studies with dairy cows (Bionaz and Loor, 2011) and mice (Chat et al., 2011) have revealed important functions for mTOR signaling and SNARE proteins during lactation, underscoring the potential importance of our findings in the context of mastitis infection. In neutrophils, the SNARE protein complexes are essential for extracellular release of cytoplasmic granules as a means to combat infectious pathogens during infection (Mollinedo et al., 2006). Thus, the activation of vesicular transport via SNARE proteins might have served as a defense mechanism to destroy Strep. uberis. A detailed analysis of angiogenesis with respect to inflammation has been discussed in our previous report dealing with the mammary transcriptome (Moyes et al., 2009a).

Previous work with different mastitis pathogens revealed that IL1B plays a central role in promoting mammary cell apoptosis during IMI (Zhao and Lacasse, 2008). The high impact and activation of "interleukin-1 binding" and "interleukin-1 receptor activity" (Supplementary Table 12, available online athttp:// 
www.journalofdairyscience.org/) among target genes regulated by miR-31 coupled with the $\sim 40$-fold upregulation of IL1R2 (Moyes et al., 2009a) seems to support a role for this miRNA in controlling the balance between mammary cell apoptosis or proliferation during infection. In mammary cancer cell lines with a defective p53 signaling pathway, the overexpression of miR-31 inhibited proliferation and induced apoptosis; however, in wild-type cells, miR-31 had no effect (Creighton et al., 2010). In other studies, blocking miR-31 expression reduced growth of tumor xenografts (Liu et al., 2010). Our data suggest that miR-31 could play a similar role in bovine mammary epithelial cells (i.e., apoptotic pathways per se were not among the most affected, whereas several associated with cell survival and angiogenesis were activated; Figure 2). However, the inhibition of mTOR signaling and phosphatidylinositol (miR-181a) also suggests a link between miR-31 and apoptosis because these pathways are commonly disrupted in breast cancer (Hernandez-Aya and Gonzalez-Angulo, 2011). We recently demonstrated that both mTOR and JAK-STAT pathways in bovine mammary tissue are upregulated during established lactation and likely help coordinate mammary protein synthesis and the control of proliferation versus apoptosis (Bionaz and Loor, 2011).

\section{CONCLUSIONS}

Bioinformatics analysis of miRNA and target gene expression provided a more holistic view of the underlying mechanisms affected by IMI with Strep. uberis. Differential expression of miR-16a, -31,-181a, and -223 provided evidence for the involvement of miRNA in controlling not only immune response but also cellular signaling, survival, and metabolism. Most of the differentially expressed miRNA were downregulated with IMI; however, because several target genes are regulated by more than 1 miRNA, it appears likely that a coordinated network of control exists among miRNA. The KEGG analysis suggested an inhibitory effect of most miRNA on metabolic pathways but an induction of the immune response. Because the inflammatory response to infection must be robust enough to destroy invading pathogens but also be resolved in a timely manner to avoid excessive damage to host cells, it is not surprising that the miRNA in this study appeared to be involved in both aspects of inflammation. The relevance of altered miRNA expression to immune response in mammary cells remains to be elucidated. We identified several potential miRNA-mRNA associations underlying several biological pathways related to the immune response. Our study does not exclude the possibility that these miRNA may directly or indirectly influence mammary tissue tolerance to infection. Overall, compelling evidence now exists for the regulation of immune activation, immune cell differentiation, and regulation of immune response and metabolism by miRNA. Thus, the identification of miRNA and their respective targets may offer new therapeutic strategies to treat immunological and infectious diseases such as mastitis.

\section{ACKNOWLEDGMENTS}

The authors extend gratitude to the University of Illinois Dairy Research Unit (Urbana) staff for animal care during the study. K. Zhong was supported by a scholarship from the China Scholarship Council (Beijing, China).

\section{REFERENCES}

Abell, K., and C. J. Watson. 2005. The Jak/Stat pathway: A novel way to regulate PI3K activity. Cell Cycle 4:897-900.

Bar, D., L. W. Tauer, G. Bennett, R. N. Gonzalez, J. A. Hertl, Y. H. Schukken, H. F. Schulte, F. L. Welcome, and Y. T. Grohn. 2008. The cost of generic clinical mastitis in dairy cows as estimated by using dynamic programming. J. Dairy Sci. 91:2205-2214.

Benson, R. A., J. A. Lowrey, J. R. Lamb, and S. E. Howie. 2004. The Notch and Sonic hedgehog signalling pathways in immunity. Mol. Immunol. 41:715-725.

Bionaz, M., and J. J. Loor. 2011. Gene networks driving bovine mammary protein synthesis during the lactation cycle. Bioinform. Biol. Insights 5:83-98.

Bionaz, M., K. Periasamy, S. L. Rodriguez-Zas, W. L. Hurley, and J. J. Loor. 2012. A novel dynamic impact approach (DIA) for functional analysis of time-course omics studies: Validation using the bovine mammary transcriptome. PLoS ONE 7:e32455.

Bruns, A. M., and C. M. Horvath. 2012. Activation of RIG-I-like receptor signal transduction. Crit. Rev. Biochem. Mol. Biol. 47:194-206.

Capuco, A. V., E. E. Connor, and D. L. Wood. 2008. Regulation of mammary gland sensitivity to thyroid hormones during the transition from pregnancy to lactation. Exp. Biol. Med. (Maywood) 233:1309-1314.

Chat, S., S. Layani, C. Mahaut, C. Henry, E. Chanat, and S. Truchet. 2011. Characterisation of the potential SNARE proteins relevant to milk product release by mouse mammary epithelial cells. Eur. J. Cell Biol. 90:401-413.

Chen, C. Z., L. Li, H. F. Lodish, and D. P. Bartel. 2004. MicroRNAs modulate hematopoietic lineage differentiation. Science 303:8386.

Clarkson, R. W., M. T. Wayland, J. Lee, T. Freeman, and C. J. Watson. 2004. Gene expression profiling of mammary gland development reveals putative roles for death receptors and immune mediators in post-lactational regression. Breast Cancer Res. 6:R92R109.

Creighton, C. J., M. D. Fountain, Z. Yu, A. K. Nagaraja, H. Zhu, M. Khan, E. Olokpa, A. Zariff, P. H. Gunaratne, M. M. Matzuk, and M. L. Anderson. 2010. Molecular profiling uncovers a p53-associated role for microRNA-31 in inhibiting the proliferation of serous ovarian carcinomas and other cancers. Cancer Res. 70:1906-1915.

Dave, R. S., and K. Khalili. 2010. Morphine treatment of human monocyte-derived macrophages induces differential miRNA and protein expression: Impact on inflammation and oxidative stress in the central nervous system. J. Cell. Biochem. 110:834-845.

Dilda, F., G. Gioia, L. Pisani, L. Restelli, C. Lecchi, F. Albonico, V. Bronzo, M. Mortarino, and F. Ceciliani. 2012. Escherichia coli li- 
popolysaccharides and Staphylococcus aureus enterotoxin B differentially modulate inflammatory microRNAs in bovine monocytes. Vet. J. 192:514-516.

Eis, P. S., W. Tam, L. Sun, A. Chadburn, Z. Li, M. F. Gomez, E. Lund, and J. E. Dahlberg. 2005. Accumulation of miR-155 and $B I C$ RNA in human B cell lymphomas. Proc. Natl. Acad. Sci. USA 102:3627-3632.

Fazi, F., A. Rosa, A. Fatica, V. Gelmetti, M. L. De Marchis, C. Nervi, and I. Bozzoni. 2005. A minicircuitry comprised of microRNA-223 and transcription factors NFI-A and $\mathrm{C} / \mathrm{EBP} \alpha$ regulates human granulopoiesis. Cell 123:819-831.

Günther, J., D. Koczan, W. Yang, G. Nürnberg, D. Repsilber, H.-J. Schuberth, Z. Park, N. Maqbool, A. Molenaar, and H.-M. Seyfert. 2009. Assessment of the immune capacity of mammary epithelial cells: Comparison with mammary tissue after challenge with Escherichia coli. Vet. Res. 40:31.

Harmon, R. J. 1994. Physiology of mastitis and factors affecting somatic cell counts. J. Dairy Sci. 77:2103-2112.

Hensen, S. M., M. J. Pavicić, J. A. Lohuis, and B. Poutrel. 2000. Use of bovine primary mammary epithelial cells for the comparison of adherence and invasion ability of Staphylococcus aureus strains. J. Dairy Sci. 83:418-429.

Hernandez-Aya, L. F., and A. M. Gonzalez-Angulo. 2011. Targeting the phosphatidylinositol 3-kinase signaling pathway in breast cancer. Oncologist 16:404-414.

Himpe, E., C. Degaillier, A. Coppens, and R. Kooijman. 2008. Insulinlike growth factor-1 delays Fas-mediated apoptosis in human neutrophils through the phosphatidylinositol-3 kinase pathway. J. Endocrinol. 199:69-80.

Inoue, T., H. Saito, T. Matsuda, K. Fukatsu, I. Han, S. Furukawa, S. Ikeda, and T. Muto. 1998. Growth hormone and insulin-like growth factor I augment bactericidal capacity of human polymorphonuclear neutrophils. Shock 10:278-284.

Jing, Q., S. Huang, S. Guth, T. Zarubin, A. Motoyama, J. Chen, F. Di Padova, S.-C. Lin, H. Gram, and J. Han. 2005. Involvement of microRNA in AU-rich element-mediated mRNA instability. Cell 120:623-634.

Johnnidis, J. B., M. H. Harris, R. T. Wheeler, S. Stehling-Sun, M. H. Lam, O. Kirak, T. R. Brummelkamp, M. D. Fleming, and F. D. Camargo. 2008. Regulation of progenitor cell proliferation and granulocyte function by microRNA-223. Nature 451:1125-1129.

Kim, V. N., J. Han, and M. C. Siomi. 2009. Biogenesis of small RNAs in animals. Nat. Rev. Mol. Cell Biol. 10:126-139.

Kunisada, K., H. Hirota, Y. Fujio, H. Matsui, Y. Tani, K. YamauchiTakihara, and T. Kishimoto. 1996. Activation of JAK-STAT and MAP kinases by leukemia inhibitory factor through gp130 in cardiac myocytes. Circulation 94:2626-2632.

Landgraf, P., M. Rusu, R. Sheridan, A. Sewer, N. Iovino, A. Aravin, S. Pfeffer, A. Rice, A. O. Kamphorst, M. Landthaler, C. Lin, N. D. Socci, L. Hermida, V. Fulci, S. Chiaretti, R. Foà, J. Schliwka, U. Fuchs, A. Novosel, R.-U. Müller, B. Schermer, U. Bissels, J. Inman, Q. Phan, M. Chien, D. B. Weir, R. Choksi, G. De Vita, D. Frezzetti, H.-I. Trompeter, V. Hornung, G. Teng, G. Hartmann, M. Palkovits, R. Di Lauro, P. Wernet, G. Macino, C. E. Rogler, J. W. Nagle, J. Ju, F. N. Papavasiliou, T. Benzing, P. Lichter, W. Tam, M. J. Brownstein, A. Bosio, A. Borkhardt, J. J. Russo, C. Sander, M. Zavolan, and T. Tuschl. 2007. A mammalian microRNA expression atlas based on small RNA library sequencing. Cell 129:1401-1414.

Lewis, B. P., I. H. Shih, M. W. Jones-Rhoades, D. P. Bartel, and C. B. Burge. 2003. Prediction of mammalian microRNA targets. Cell 115:787-798.

Li, Q.-J., J. Chau, P. J. R. Ebert, G. Sylvester, H. Min, G. Liu, R. Braich, M. Manoharan, J. Soutschek, P. Skare, L. O. Klein, M. M. Davis, and C.-Z. Chen. 2007. miR-181a is an intrinsic modulator of T cell sensitivity and selection. Cell 129:147-161.

Lindsay, M. A. 2008. MicroRNAs and the immune response. Trends Immunol. 29:343-351.

Linsley, P. S., J. Schelter, J. Burchard, M. Kibukawa, M. M. Martin, S. R. Bartz, J. M. Johnson, J. M. Cummins, C. K. Raymond, H. Dai, N. Chau, M. Cleary, A. L. Jackson, M. Carleton, and L. Lim. 2007.
Transcripts targeted by the microRNA-16 family cooperatively regulate cell cycle progression. Mol. Cell. Biol. 27:2240-2252.

Liu, C.-J., M.-M. Tsai, P.-S. Hung, S.-Y. Kao, T.-Y. Liu, K.-J. Wu, S.-H. Chiou, S.-C. Lin, and K.-W. Chang. 2010. miR-31 ablates expression of the HIF regulatory factor FIH to activate the HIF pathway in head and neck carcinoma. Cancer Res. 70:1635-1644.

Liu, G., A. Friggeri, Y. Yang, Y.-J. Park, Y. Tsuruta, and E. Abraham. 2009. miR-147, a microRNA that is induced upon toll-like receptor stimulation, regulates murine macrophage inflammatory responses. Proc. Natl. Acad. Sci. USA 106:15819-15824.

Loor, J. J., K. M. Moyes, and M. Bionaz. 2011. Functional adaptations of the transcriptome to mastitis-causing pathogens: The mammary gland and beyond. J. Mammary Gland Biol. Neoplasia 16:305-322.

Lu, L. F., T. H. Thai, D. P. Calado, A. Chaudhry, M. Kubo, K. Tanaka, G. B. Loeb, H. Lee, A. Yoshimura, K. Rajewsky, and A. Y. Rudensky. 2009. Foxp3-dependent microRNA155 confers competitive fitness to regulatory $\mathrm{T}$ cells by targeting SOCS1 protein. Immunity 30:80-91.

Lutzow, Y. S., C. Gray, and R. Tellam. 2008. 15-Deoxy-delta12,14prostaglandin J2 induces chemokine expression, oxidative stress and microfilament reorganization in bovine mammary epithelial cells. J. Dairy Res. 75:55-63.

Menzies, K. K., C. Lefèvre, K. L. Macmillan, and K. R. Nicholas. 2009. Insulin regulates milk protein synthesis at multiple levels in the bovine mammary gland. Funct. Integr. Genomics 9:197-217.

Mollinedo, F., J. Calafat, H. Janssen, B. Martín-Martín, J. Canchado, S. M. Nabokina, and C. Gajate. 2006. Combinatorial SNARE complexes modulate the secretion of cytoplasmic granules in human neutrophils. J. Immunol. 177:2831-2841.

Moyes, K. M., J. K. Drackley, D. E. Morin, M. Bionaz, S. L. Rodriguez-Zas, R. E. Everts, H. A. Lewin, and J. J. Loor. 2009a. Gene network and pathway analysis of bovine mammary tissue challenged with Streptococcus uberis reveals induction of cell proliferation and inhibition of $\operatorname{PPAR} \gamma$ signaling as potential mechanism for the negative relationships between immune response and lipid metabolism. BMC Genomics 10:542.

Moyes, K. M., J. K. Drackley, D. E. Morin, and J. J. Loor. 2010. Greater expression of TLR2, TLR4, and IL6 due to negative energy balance is associated with lower expression of $H L A-D R A$ and $H L A-A$ in bovine blood neutrophils after intramammary mastitis challenge with Streptococcus uberis. Funct. Integr. Genomics 10:53-61.

Moyes, K. M., J. K. Drackley, J. L. Salak-Johnson, D. E. Morin, J. C. Hope, and J. J. Loor. 2009b. Dietary-induced negative energy balance has minimal effects on innate immunity during a Streptococcus uberis mastitis challenge in dairy cows during midlactation. J. Dairy Sci. 92:4301-4316.

Nahid, M. A., M. Satoh, and E. K. L. Chan. 2011. Mechanistic role of microRNA-146a in endotoxin-induced differential cross-regulation of TLR signaling. J. Immunol. 186:1723-1734.

O'Connell, R. M., A. A. Chaudhuri, D. S. Rao, and D. Baltimore. 2009. Inositol phosphatase SHIP1 is a primary target of miR-155. Proc. Natl. Acad. Sci. USA 106:7113-7118.

Ozes, O. N., L. D. Mayo, J. A. Gustin, S. R. Pfeffer, L. M. Pfeffer, and D. B. Donner. 1999. NF-kappaB activation by tumour necrosis factor requires the Akt serine-threonine kinase. Nature 401:82-85.

Phillips, D. J. 2005. Activins, inhibins and follistatins in the large domestic species. Domest. Anim. Endocrinol. 28:1-16.

Piantoni, P., P. Wang, J. K. Drackley, W. L. Hurley, and J. J. Loor. 2010. Expression of metabolic, tissue remodeling, oxidative stress, and inflammatory pathways in mammary tissue during involution in lactating dairy cows. Bioinform. Biol. Insights 4:85-97.

Popova, T., V. Espina, C. Bailey, L. Liotta, E. Petricoin, and S. Popov. 2009. Anthrax infection inhibits the AKT signaling involved in the E-cadherin-mediated adhesion of lung epithelial cells. FEMS Immunol. Med. Microbiol. 56:129-142.

Rinaldi, M., R. W. Li, and A. V. Capuco. 2010. Mastitis associated transcriptomic disruptions in cattle. Vet. Immunol. Immunopathol. 138:267-279. 
Schere-Levy, C., V. Buggiano, A. Quaglino, A. Gattelli, M. C. Cirio, I. Piazzon, S. Vanzulli, and E. C. Kordon. 2003. Leukemia inhibitory factor induces apoptosis of the mammary epithelial cells and participates in mouse mammary gland involution. Exp. Cell Res. 282:35-47.

Su, Y., F. A. Simmen, R. Xiao, and R. C. Simmen. 2007. Expression profiling of rat mammary epithelial cells reveals candidate signaling pathways in dietary protection from mammary tumors. Physiol. Genomics 30:8-16.

Szepietowski, J. C., A. Reich, and R. C. McKenzie. 2004. The multifunctional role of leukaemia inhibitory factor in cutaneous biology. Acta Dermatovenerol. Alp. Panonica Adriat. 13:125-129.

Taganov, K. D., M. P. Boldin, K.-J. Chang, and D. Baltimore. 2006. NF- $\kappa$ B-dependent induction of microRNA miR-146, an inhibitor targeted to signaling proteins of innate immune responses. Proc. Natl. Acad. Sci. USA 103:12481-12486.

Tam, W., and J. E. Dahlberg. 2006. $m i R-155 / B I C$ as an oncogenic microRNA. Genes Chromosomes Cancer 45:211-212.

Tili, E., J.-J. Michaille, and G. A. Calin. 2008. Expression and function of micro-RNAs in immune cells during normal or disease state. Int. J. Med. Sci. 5:73-79.

Vergoulis, T., I. S. Vlachos, P. Alexiou, G. Georgakilas, M. Maragkakis, M. Reczko, S. Gerangelos, N. Koziris, T. Dalamagas, and A.
G. Hatzigeorgiou. 2012. TarBase 6.0: Capturing the exponential growth of miRNA targets with experimental support. Nucleic Acids Res. 40:D222-D229.

Vigorito, E., K. L. Perks, C. Abreu-Goodger, S. Bunting, Z. Xiang, S. Kohlhaas, P. P. Das, E. A. Miska, A. Rodriguez, A. Bradley, K. G. Smith, C. Rada, A. J. Enright, K. M. Toellner, I. C. Maclennan, and M. Turner. 2007. microRNA-155 regulates the generation of immunoglobulin class-switched plasma cells. Immunity $27: 847-859$.

Wesson, C. A., J. Deringer, L. E. Liou, K. W. Bayles, G. A. Bohach, and W. R. Trumble. 2000. Apoptosis induced by Staphylococcus aureus in epithelial cells utilizes a mechanism involving caspases 8 and 3. Infect. Immun. 68:2998-3001.

Worm, J., J. Stenvang, A. Petri, K. S. Frederiksen, S. Obad, J. Elmén, M. Hedtjärn, E. M. Straarup, J. B. Hansen, and S. Kauppinen. 2009. Silencing of microRNA-155 in mice during acute inflammatory response leads to derepression of c/ebp beta and down-regulation of G-CSF. Nucleic Acids Res. 37:5784-5792.

Zhao, X., and P. Lacasse. 2008. Mammary tissue damage during bovine mastitis: Causes and control. J. Anim. Sci. 86:57-65. 